\title{
Steroid implants and markers of bone turnover in steers
}

\author{
S.M. Knetter, T.J. Baxa, K.Y. Chung ${ }^{1}$, B.J. Johnson ${ }^{1}$ \& J.E. Minton ${ }^{\#}$ \\ Department of Animal Sciences and Industry, Weber Hall, Kansas State University, Manhattan, \\ KS 66506-0201, USA
}

\author{
Copyright resides with the authors in terms of the Creative Commons Attribution 2.5 South African Licence. \\ See: http://creativecommons.org/licenses/by/2.5/za \\ Condition of use: The user may copy, distribute, transmit and adapt the work, but must recognise the authors and the \\ South African Journal of Animal Science.
}

\begin{abstract}
Steroidal implants are used extensively in beef cattle management to take advantage of welldocumented improvements in growth performance and efficiency. In addition to muscle growth, steroids bring about changes in bone and cartilage formation, hastening bone ageing. The current study was designed to test the hypothesis that recently identified indicators of bone and cartilage turnover could be detected in the peripheral circulation, and that these markers might reflect accelerated ageing effects of the widely used steroidal implants, trenbolone acetate (TBA) and estradiol-17 $\beta$ (E2). Thirty-two crossbred yearling steers were given one of four treatments to determine whether these markers of bone turnover could be detected and reflect steroid-induced bone maturity in the periphery: non-implanted controls; $25.7 \mathrm{mg}$ estradiol-17 $\beta$ (E2); $120 \mathrm{mg}$ trenbolone acetate (TBA); or $120 \mathrm{mg}$ TBA and $24 \mathrm{mg}$ E2 (T+E). Blood was collected on days $0,7,14$ and 28 and serum analysed by ELISA for concentrations of IGF-I, osteocalcin, C-terminal telopeptides of Type I collagen (CTX-I) and C-terminal telopeptides of Type II collagen (CTX-II), as markers of the somatotropic-endocrine axis, bone formation, bone resorption and cartilage resorption, respectively. Circulating IGF-I was greater in E2 or T+E treated steers than controls on days 7 and 14. Osteocalcin was unaffected by treatment, but increased from day 0 on days 7,14 and 28. Treatment did not affect CTX-I. However, CTX-II was elevated in the treated animals as opposed to the controls. Although these markers of bone and cartilage turnover are detectable, results suggest that implant-induced changes are not evident in the circulatory system.
\end{abstract}

Keywords: Bone, cartilage, cattle, oestradiol 17- $\beta$, growth, trenbolone acetate

${ }^{\#}$ Corresponding author: eminton@ksu.edu

${ }^{1}$ Current address: Department of Animal and Food Sciences, Texas Tech University, P.O. Box 42141, Lubbock, TX 79409, USA

\section{Introduction}

The practice of administering androgenic and estrogenic steroid implants to increase lean tissue accretion and decrease adipose tissue deposition in feedlot cattle is well established. Yearling steers implanted with a combination of trenbolone acetate (TBA) and estradiol-17 (E2) show an increase in average daily gain (18\% to $21 \%)$, feed efficiency $(13 \%)$ and muscle size when compared with nonimplanted steers (Johnson et al., 1996a). In addition, steroid implants increase circulating concentrations of insulin-like growth factor I (IGF-I) and muscle IGF-I mRNA levels by d 7 after implantation (Pampusch et al., 2003). However, less is known about the impacts of these practices on bone growth and the metabolites that affect bone ageing. The same implantation system increased the percentage ash content of the cartilage of the 9th to 11 th thoracic vertebrae and consequently advanced bone maturity scores (Reiling \& Johnson, 2003). When implanted with E2 only, Kniffen et al. (1999) found a dosage-dependent advancement in epiphyseal plate closure of metacarpal bones III and IV in beef heifers. Together, the data suggest that TBA, E2, or in combination, may hasten bone ageing and, in this way, indirectly affect carcass quality. Bone ageing has implications for the value of beef carcasses because in some markets advanced bone age is associated with poorer beef quality, and devalues the carcass. Little is currently known about the mechanisms of action behind this effect and whether peripheral indicators of bone and cartilage metabolism might be reflective of 
implant-driven alterations in these tissues. We evaluated total IGF-I to document expected changes in the somatotropic axis in response to implantation and circulating osteocalcin and C-terminal telopeptides of Type I collagen (CTX-I) as peripheral markers of bone formation and resorption, respectively. C-terminal telopeptides of Type II collagen (CTX-II) were likewise evaluated as a systemic indicator of cartilage resorption. It was hypothesized that these indicators of bone and cartilage turnover could be detected in the peripheral circulation. Furthermore, it was hypothesized that these peripheral markers might reflect accelerated ageing effects of the widely used steroidal implants, trenbolone acetate (TBA) and estradiol-17 $\beta$ (E2).

\section{Materials and Methods}

All animal-related experimental procedures were approved by the Kansas State University Institutional Animal Care and Use Committee.

Thirty-two crossbred yearling steers with an average initial body weight (BW) of $379 \pm 2.9 \mathrm{~kg}$ were divided by BW into four blocks and randomly assigned to one of four treatments within each block in a $2 \times 2$ factorial design: 1) non-implanted, control; 2) implanted with $25.7 \mathrm{mg}$ E2 (Compudose, Vetlife Inc., West Des Moines, IA; E2); 3) implanted with $120 \mathrm{mg}$ of trenbolone acetate (Finaplix, Intervet Inc., Millsboro, DE; TBA); 4) implanted with $120 \mathrm{mg}$ TBA and $24 \mathrm{mg}$ E2 in combination (Revalor-S, Intervet Inc., Millsboro, DE; T+E). Steers began the experiment in two groups, four weeks apart. Animals were acclimated to a $93 \%$ concentrate diet fed ad libitum in individual pens beginning $21 \mathrm{~d}$ before implantation. On $\mathrm{d} 0$, steers received a steroidal implant subcutaneously in the middle third of the right ear whereas control steers received no implant. On d 0, d 7, d 14 and d 28, blood samples were collected by jugular venipuncture for serum analysis. Samples were obtained consistently from the right jugular vein (ipsilateral to the ear containing the implant). Samples clotted overnight at $4{ }^{\circ} \mathrm{C}$, then were warmed on the countertop to approximately 20 to 25 ${ }^{\circ} \mathrm{C}$. Serum was then obtained by centrifugation $\left(1500 \times \mathrm{g}\right.$, for $20 \mathrm{~min}$ at $\left.4{ }^{\circ} \mathrm{C}\right)$, divided into aliquots and stored at $-20{ }^{\circ} \mathrm{C}$ until use. Steer management, including diet and implantation protocol, were identical to a companion study reported previously (Chung et al., 2012). In brief, the diet was a steam flaked maize and ground lucerne hay based diet that provided (dry matter basis) $135.6 \mathrm{~g}$ crude protein, $141.5 \mathrm{~g}$ neutral detergent fibre, 19.3 $\mathrm{MJ} \mathrm{NE}_{\mathrm{m}} / \mathrm{kg}$ and $13.1 \mathrm{MJ} \mathrm{NE}_{\mathrm{g}} / \mathrm{kg}$.

Concentrations of IGF-I (OCTEIA IGF-I; AC-27F1), osteocalcin (Rat-MID Osteocalcin ELISA kit; AC-11F1), CTX-I (CrossLaps for Culture ELSIA kit; 6CRL4000), and CTX-II (Urine CartiLaps ELISA kit; AC-10F1) were measured by enzyme-linked immunosorbent assays (ELISA) according to the kit protocols or as modified according to suggestions from the manufacturer (Immunodiagnostic Systems Ltd., Fountain Hills, AZ). Internal data from the manufacturer were obtained to document immunoreactivity in bovine serum for osteocalcin, CTX-I, and CTX-II. The assays for CTX-I and CTX-II were modified slightly to accommodate measurement in serum. The modification to the protocol simply involved a five-fold dilution of the test serum following guidance from the manufacturer. No data, however, were available for the IGF-I ELISA in bovine serum, so the assay was validated in our laboratory. When IGF-I was added to bovine serum and tested in the ELISA, the concentration of IGF-I measured in the assay averaged $92.3 \%$ of the expected concentration, demonstrating acceptable quantitative recovery of added mass. The IGF-I ELISA protocol called for $50 \mu \mathrm{L}$ of serum. To evaluate the assay for the absence of interfering serum matrix effects, samples of bovine serum were diluted $1: 2,1: 3.33$, and $1: 5$ and evaluated in the ELISA. When corrected for dilution, the measured concentrations averaged $105 \%$ of the expected concentration. The ELISA was sensitive to $14 \mathrm{ng} / \mathrm{mL}$. All samples were assayed in two plates. The intra-assay CV averaged $6.4 \%$ and the inter-assay CV was $6.9 \%$. The IGF-I ELISA protocol utilized a proprietary releasing agent to allow release of IGF-I from binding proteins and, therefore, was assumed to estimate total IGF-I.

All serum data were analysed as a randomized block design with repeated measures using the mixed model procedure (SAS Inst. Inc., Cary, N.C.). The model included effects of implant treatment, time after implant, replicate, block and all interactive terms. The effects of weight block, replicate and their interactions were considered random effects in the model. Implant treatment, time and the treatment $\mathrm{x}$ time interaction were considered fixed effects. The heterogeneous compound symmetry option was used in the repeated measures command. Least square means were compared by using the PDIFF option only when there was a significant $\mathrm{F}$ test $(P<0.05)$ for the main effects of treatment, time or the treatment $\mathrm{x}$ time interaction in the analysis of variance. 


\section{Results}

There was an interaction between treatment and time $(P<0.05)$ for serum concentrations of IGF-I (Figure 1). Circulating IGF-I was similar among treatments on $\mathrm{d} 0$ and $\mathrm{d} 28$. At $\mathrm{d} 7$ and $\mathrm{d} 14$, steers receiving $\mathrm{E} 2$ or $\mathrm{T}+\mathrm{E}$ had greater circulating IGF-I than non-implanted control steers $(P<0.05)$. By contrast, steers receiving only TBA tended (but not significantly) to have elevated IGF-I compared with controls on $\mathrm{d} 7$ and $\mathrm{d} 14(P=0.10)$.

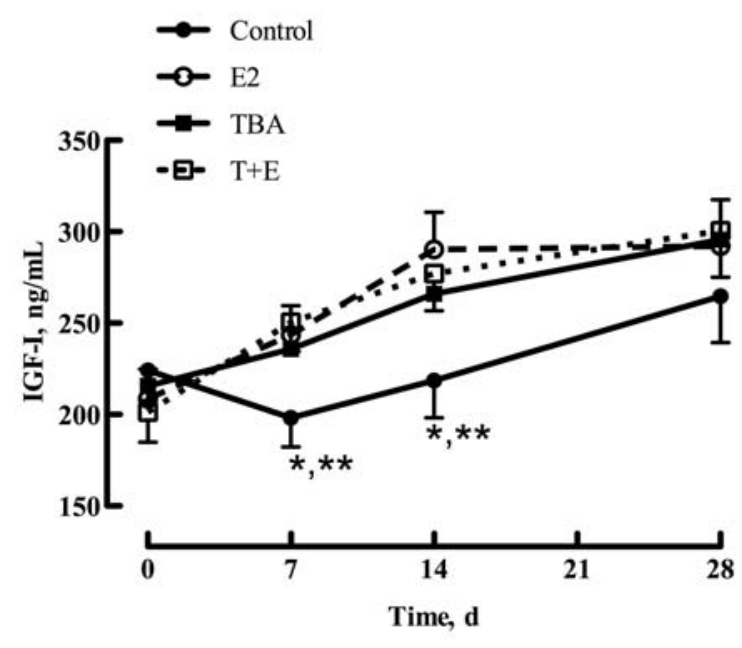

Figure 1 Effect of steroid implant treatment on serum insulin-like growth factor I (IGF-I) in steers implanted with estradiol-17 $\beta$ (E2), trenbolone acetate (TBA), a combination $(\mathrm{T}+\mathrm{E})$ and non-implanted controls. Data points represent the least square means $( \pm$ SEM) of eight steers per treatment. Asterisks indicate days on which IGF-I concentration was greater than controls for $\mathrm{E} 2$ and $\mathrm{T}+\mathrm{E}(* P<0.05)$ and tended to be greater for TBA $(* * P=0.10)$.

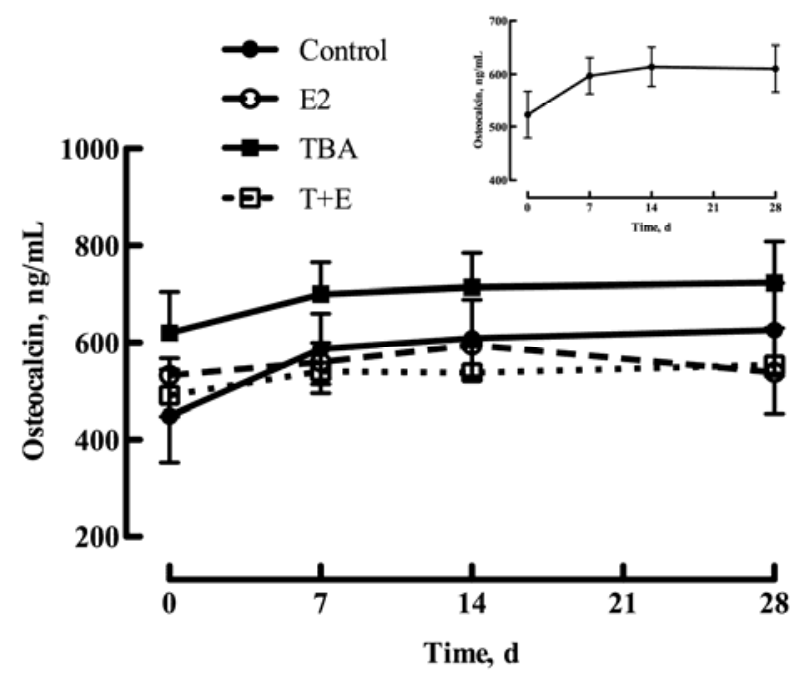

Figure 2 Effect of steroid implant treatment on serum osteocalcin in steers implanted with estradiol-17 $\beta$ (E2), trenbolone acetate (TBA), a combination (T+E) and non-implanted controls. Data points represent the least square means $( \pm$ SEM) of four to six steers per treatment. Figure insert depicts time main effect means. Concentrations of osteocalcin were increased on $\mathrm{d} 7,14$, and 28 compared to $\mathrm{d} 0(P<0.005$ for all comparisons). 
Osteocalcin serum concentrations (Figure 2) were not affected by treatment, but there was a significant effect of time $(P<0.01)$. All treatment groups including the control non-implanted steers had a significant increase in osteocalcin levels from $\mathrm{d} 0$ to $\mathrm{d} 7$, to $\mathrm{d} 14$ and to $\mathrm{d} 28(P<0.01)$. However, there was no significant difference in osteocalcin concentrations over time measured at $\mathrm{d} 7$ and $\mathrm{d} 14$, or between $\mathrm{d} 14$ and d 28 .

Estimates of bone turnover as reflected by Type I collagen degradation (CTX-I; Figure 3) were not affected by treatment or time. There were considerable variations between animals within days and treatments. For example, values ranged from $45.6 \mathrm{nM}$ in a $\mathrm{T}+\mathrm{E}$ implanted steer on $\mathrm{d} 0$ to $345.0 \mathrm{nM}$ in a different $\mathrm{T}+\mathrm{E}$ implanted steer, also on $\mathrm{d} 0$.

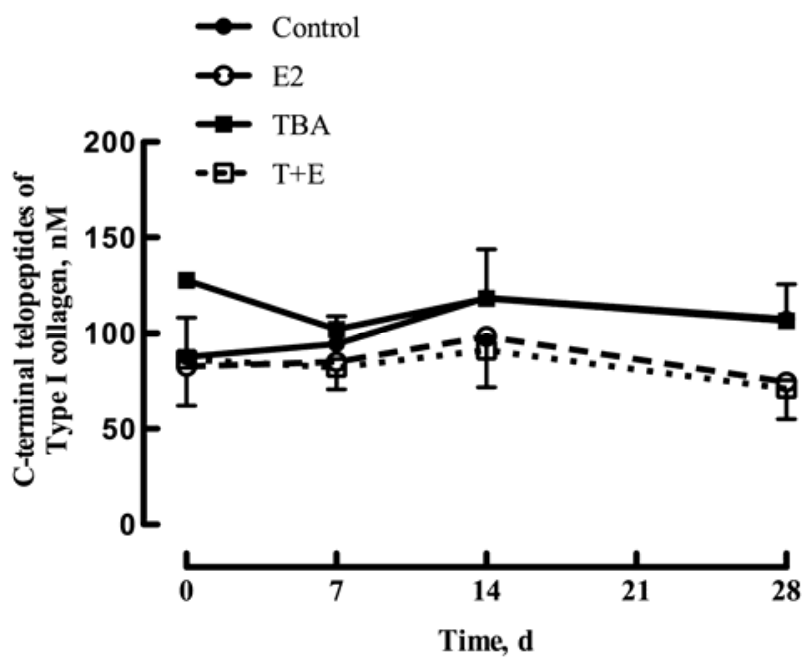

Figure 3 Effect of steroid implant treatment on C-terminal telopeptides of Type I collagen, a measure of bone resorption, in steers implanted with estradiol-17 $(\mathrm{E} 2)$, trenbolone acetate (TBA), a combination (T+E), and non-implanted controls. Serum was obtained by jugular venipuncture on d 0 prior to implantation, and after 7, 14 and $28 \mathrm{~d}$. Data points represent the least square means ( \pm SEM) of eight steers per treatment.

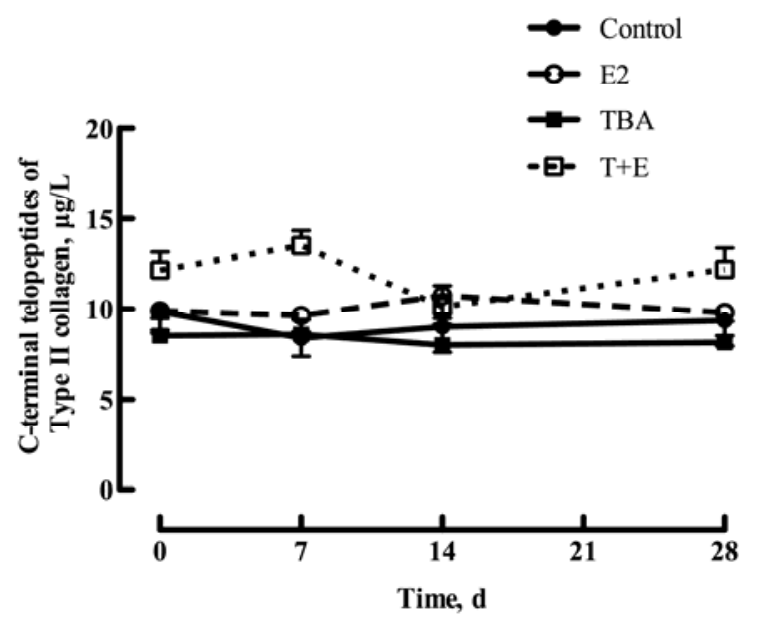

Figure 4 Effect of steroid implant treatment on C-terminal telopeptides of Type II collagen, a measure of cartilage resorption, in steers implanted with estradiol-17 $\beta$ (E2), trenbolone acetate (TBA), a combination $(\mathrm{T}+\mathrm{E})$, and non-implanted controls. Serum was obtained by jugular venipuncture on $\mathrm{d} 0$ prior to implantation, and after 7, 14, and $28 \mathrm{~d}$. Data points represent the least-square means ( \pm SEM) of four to six steers per treatment. 
Serum concentrations of CTX-II (Figure 4) were not significantly affected by time, but there was a significant treatment effect in the analysis of variance $(P<0.05)$. When compared with the control group, the $\mathrm{T}+\mathrm{E}$ implant had elevated CTX-II concentrations $(P<0.05)$. Concentration of CTX-II also tended to be higher in $\mathrm{T}+\mathrm{E}$ steers compared with $\mathrm{E} 2(P<0.08)$.

\section{Discussion}

It has been well documented that steroid growth promotant implants have positive effects on the efficiency and growth of livestock animals, and much is known about the cellular mechanisms behind the changes in muscle (Foutz et al., 1997; Johnson et al., 1998; Barton-Davis et al., 1999; Pampusch et al., 2008). However, there is no current literature on the impacts of steroid implantation on the cellular level of bone growth and resorption that are linked to the steroid-induced increases in bone maturity. Age is a contributor to carcass grading and some international trade restrictions, and the physiological maturity of an animal is used to determine its age. Because visible ossification of cartilage is used to designate the degree of maturity, it is important to understand how implantation affects cartilage ossification, bone growth and resorption to understand the potential economic implications of steroid-induced bone ageing.

The current study was not designed specifically to determine effects of implant treatment on growth performance of steers. However, we elected to measure circulating IGF-I as an indirect positive marker of responses of cattle to growth-promoting steroid implants (Johnson et al., 1996b; Johnson et al., 1998). Additionally, it has been previously shown that implants containing $\mathrm{E} 2$ or $\mathrm{T}+\mathrm{E}$ have a greater ability to stimulate circulating IGF-I than implants containing only TBA (Pampusch et al., 2008). Indeed, our results show a similar finding, and may indicate a greater capability for E2 to affect serum IGF-I concentrations. However, IGF-I mRNA in bovine satellite cell cultures was equally stimulated by E2 and TBA treatment (Kamanga-Sollo et al., 2008), which may suggest a different mechanism to promote locally produced IGF-I in these cells. It is possible that the disparity between local production and circulating IGF-I is due to receptor differences and/or response endocrine pathway differences between E2 and TBA implants, and this could be consistent across tissues, including bone. The E2 implant used in this study is also a longer-acting implant, and it is possible that if measured for longer than $28 \mathrm{~d}$, even greater changes in IGF-I may be evident. When fed a high plane of nutrition similar to a feedlot finishing diet, plasma growth hormone IGF-I and the high-affinity hepatic somatotropic receptor were increased when treated with E2 (Breier et al., 1988). This may be further evidence that E2 and other oestrogens act on the somatotropic axis to increase hepatic secretion of IGF-I, while TBA and other androgens act through a yet-unidentified mechanism. An increase in bone maturity scores when compared with nonimplanted controls has been associated with oestrogens (Turner et al., 1995), androgens (Moran et al., 1991) and the steroids in combination (Reiling \& Johnson, 2003). Until now, however, there has not been a comparative study that evaluates serum IGF-I where treatments included E2 and TBA alone and where those amounts of E2 and TBA were represented exactly in a third combination treatment. This potentially eliminates dosage differences and can help clarify treatment differences.

Similar to IGF-I, osteocalcin increased over time. As a marker of osteoblast activity, osteocalcin levels can indicate the ossification or formation of bone. Given the well-documented increases in bone maturity post implantation, we hypothesized that osteocalcin might increase as well. Although there were obvious effects of implantation on IGF-I concentrations, as noted above, the general trend for all treatment groups, including the control animals, was an increase from $\mathrm{d} 0$ to $\mathrm{d} 28$. In fact, by d 28, serum IGF-I did not differ among treatments. This general rise in IGF-I could correlate with the rise in osteocalcin seen over time, regardless of implantation. It is possible that although osteocalcin, as a marker of bone formation, did not respond to steroid treatment, it may have been responding to IGF-I effects on long bone growth and would be evident if measured in synovial fluid or another local medium. This effect of IGF-I has been shown to increase in osteoblast proliferation, osteocalcin gene expression, as well as osteocalcin concentration in cultured osteoblasts in vitro (Kudo et al., 1998; Li et al., 2009). It is likely that the steroid-induced increases in bone growth and ossification of cartilaginous tissue are a result of stimulated osteoblast activity and osteocalcin secretion.

It has been established that the process of normal bone formation associated with somatic growth involves bone and cartilage turnover. For this reason, we felt it reasonable to hypothesize that both CTX-I and CTX-II might be at steady state in a normally growing steer. We further reasoned that because bone growth and hastened maturity have been associated with steroidal implants, implantation might result in 
decreased CTX-I and elevated CTX-II, measures of bone and cartilage degradation, respectively. However, the results of our study did not confirm this hypothesis as there were no treatment by time effects for either CTX-I or CTX-II. We might speculate that changes in both bone and cartilage resorption triggered by steroid implantation and reflected in altered CTX-I and CTX-II might be evident locally at the site of bone formation, but not evident in the peripheral circulation.

There was an unexpected effect of T+E on CTX-II with this treatment having increased circulating CTX-II compared with control and a tendency to be elevated compared with E2. The reason for this difference is not readily apparent as the mean CTX-II concentrations appeared to be elevated for other treatments even on $\mathrm{d} 0$ before implantation had taken place. Additionally, if CTX-II was elevated as a result of implant-induced increases in IGF-I, it is highly unlikely that only the T+E implant and not the E2 implant would result in an increase, although it is possible that the TBA component of the combination implant is acting through an unknown mechanism to attenuate the effects of E2. It is also possible that a mechanical injury and repair of that injury, independent of treatment, may have accounted for that effect, although we feel that possibility is unlikely as there were no changes in CTX-I; nor were there signs of injury in the cattle.

\section{Conclusions}

In summary, the recently identified markers of bone and cartilage turnover, osteocalcin, CTX-I and CTX-II, are detectable in peripheral circulation. However, neither E2 nor TBA, alone or in combination, directly effected changes in the circulating concentrations of these indicators of bone formation and resorption or cartilage degradation. Because steroid treatment stimulated the somatotropic-endocrine axis in an unmistakable way (confirmed by treatment effects on IGF-I), it is concluded that local effects of steroidal implantation on bone and cartilage dynamics are not reflected in the periphery and should not be considered a reliable surrogate marker of bone age.

\section{Acknowledgements}

Contribution no. 09-394-J from the Kansas Agricultural Experiment Station. The authors thank C.M. Hill for technical assistance in the laboratory.

\section{References}

Barton-Davis, E.R., Shoturma, D.I. \& Sweeney, H.L., 1999. Contribution of satellite cells to IGF-I induced hypertrophy of skeletal muscle. Acta Physiol. Scand. 167, 301-305.

Breier, B.H., Gluckman, P.D. \& Bass, J.J., 1988. Influence of nutritional-status and oestradiol-17-beta on plasma growth-hormone, insulin-like growth factor-I and factor-II and the response to exogenous growth-hormone in young steers. J. Endocrinol. 118, 243-250.

Chung, K.Y., Baxa, T.J., Parr, S.L., Luqué, L.D. \& B.J. Johnson, B.J., 2012. Administration of estradiol, trenbolone acetate/estradiol implants alters adipogenic and myogenic gene expression in bovine skeletal muscle. J. Anim. Sci. 90,1421-1427.

Foutz, C.P., Dolezal, H.G., Gardner, T.L., Gill, D.R., Hensley, J.L. \& Morgan, J.B., 1997. Anabolic implant effects on steer performance, carcass traits, subprimal yields, and longissimus muscle properties. J. Anim. Sci. 75, 1256-1265.

Johnson, B.J., Anderson, P.T., Meiske, J.C. \& Dayton, W.R., 1996a. Effect of a combined trenbolone acetate and estradiol implant on feedlot performance, carcass characteristics, and carcass composition of feedlot steers. J. Anim. Sci. 74, 363-371.

Johnson, B.J., Hathaway, M.R., Anderson, P.T., Meiske, J.C. \& Dayton, W.R., 1996b. Stimulation of circulating insulin-like growth factor I (IGF-I) and insulin-like growth factor binding proteins (IGFBP) due to administration of a combined trenbolone acetate and estradiol implant in feedlot cattle. J. Anim. Sci. 74, 372-379.

Johnson, B.J., White, M.E., Hathaway, M.R., Christians, C.J. \& Dayton, W.R., 1998. Effect of a combined trenbolone acetate and estradiol implant on steady-state IGF-I mRNA concentrations in the liver of wethers and the longissimus muscle of steers. J. Anim. Sci. 76, 491-497.

Kamanga-Sollo, E., White, M.E., Hathaway, M.R., Chung, K.Y., Johnson, B.J. \& Dayton, W.R., 2008. Roles of IGF-I and the estrogen, androgen and IGF-I receptors in estradiol-17 beta- and trenbolone 
acetate-stimulated proliferation of cultured bovine satellite cells. Domest. Anim. Endocrinol. 35, 88-97.

Kniffen, D.M., Wagner, W.R. \& Lewis, P.E., 1999. Effects of long-term estrogen implants in beef heifers. J. Anim Sci. 77, 2886-2892.

Kudo, Y., Iwashita, M., Takeda, Y. \& Muraki, T., 1998. Evidence for modulation of osteocalcin containing gamma-carboxyglutamic acid residues synthesis by insulin-like growth factor-I and Vitamin K-2 in human osteosarcoma cell line MG-63. Eur. J. Endocrin. 138, 443-448.

Li, S.H., Guo, D. Z., Li, B., Yin, H.B., Li, J.K., Xiang, J.M. \& Deng, G.Z., 2009. The stimulatory effect of insulin-like growth factor-1 on the proliferation, differentiation, and mineralisation of osteoblastic cells from holstein cattle. Vet. J. 179, 430-436.

Moran, C., Quirke, J.F., Prendiville, D.J., Bourke, S. \& Roche, J.F., 1991. The effect of estradiol, trenbolone acetate, or zeranol on growth-rate, mammary development, carcass traits, and plasma estradiol concentrations of beef heifers. J. Anim. Sci. 69, 4249-4258.

Pampusch, M.S., Johnson, B.J., White, M.E., Hathaway, M.R., Dunn, J.D., Waylan, A.T. \& Dayton, W.R., 2003. Time course of changes in growth factor mRNA levels in muscle of steroid-implanted and nonimplanted steers. J. Anim. Sci. 81, 2733-2740.

Pampusch, M.S., White, M.E., Hathaway, M.R., Baxa, T.J., Chung, K.Y., Parr, S.L., Johnson, B.J., Weber, W.J. \& Dayton, W.R., 2008. Effects of implants of trenbolone acetate, estradiol, or both, on muscle insulin-like growth factor-I, insulin-like growth factor-I receptor, estrogen receptor-alpha, and androgen receptor messenger ribonucleic acid levels in feedlot steers. J. Anim. Sci. 86, 3418-3423.

Reiling, B.A. \& Johnson, D.D., 2003. Effects of implant regimens (trenbolone acetate-estradiol administered alone or in combination with, zeranol) and vitamin D-3 on fresh beef color and quality. J. Anim. Sci. 81, 135-142.

Turner, N.D., Greene, L.W., Byers, F.M. \& Kenison, D.C., 1995. Influence of incremental zeranol implant doses on the chemical and physical characteristics of 3rd metacarpal bone and chemical-composition of liver and soft-tissue from feedlot steers. J. Anim. Sci. 73, 1-8. 